\title{
De casa a museu: 80 anos do Museu Republicano "Convenção de ltu"
}

\section{Jonas Soares de Souza}

Museu Republicano Convenção de Itu-MP/USP

Museu Republicano "Convenção de ltu" abriu suas portas ao público no dia 18 de abril de 1923. Instalado na casa onde nesses mesmos dia e mês cinqüenta anos antes tinha sido realizada uma grande reunião de republicanos, o museu materializava um projeto de políticos ituanos e antigos membros do PRP Partido Republicano Paulista: preservar a "Casa da Convenção" para transformála em memorial da República.

Construída na década de 1850 pelo fazendeiro Francisco de Almeida Prado, a casa constou do rol de bens que ele ao falecer legou à sua segunda esposa, Ana Joaquina Vasconcelos Noronha. Em 1866, no inventário dos bens de Ana Joaquina, a casa foi destinada ao filho do casal, Carlos de Vasconcelos de Almeida Prado'. Logo que se apossou do imóvel, Carlos de Vasconcelos mandou fazer a reforma que, de acordo com o gosto então reinante na Corte, atualizou os cômodos dianteiros dos dois pavimentos e a fachada principal do sobrado. $\bigcirc$ imenso beiral que avançava na área da calçada cedeu lugar à platibanda, e a parte superior da fachada ganhou tratamento em azulejos portugueses.

São escassas as informações sobre as alterações internas, mas, como afirma Carlos Lemos (LEMOS, 1999), "é claro que os fazendeiros mais esclarecidos tratavam, dentro das possibilidades, de evitar sobretudo as alcovas abafadas e escuras, já, inclusive, condenadas também por engenheiros e tratadistas"2.

A intervenção no edifício ocorreu em 1867, como atesta a data inscrita na platibanda, e após a sua conclusão o sobrado passou a servir de residência à família de Carlos de Vasconcelos de Almeida Prado. O edifício também pode ser visto como símbolo do poder econômico do café. Na época da sua construção, muitas das antigas residências remanescentes do século anterior estavam sendo demolidas, cedendo espaços e materiais para imponentes sobrados destinados

\footnotetext{
1. Inventários de Francisco de Almeida Prado e Ana Joaquina Vasconcelos Noronha, Fundo Arquivo Central da Comarca de Itu, Museu Republicano "Convenção de Itu"/MP-USP.

2. LEMOS, Carlos A. C. Casa Paulista: história das moradias anteriores ao ecletismo trazido pelo café. São Paulo:Editora da Universidade de São Paulo, 1999. p. 211.
} 
3. LEMOS, Carlos. Testemunha da história. Boa Vida, Itu, v.15, n. 178, p.7, 2003. às moradias de fazendeiros enriquecidos pelo café. Para Carlos Lemos (LEMOS, 2003), o sobrado que abrigou a Convenção de ltu provém, certamente, dessa renovação urbana a partir do aproveitamento das velhas moradas bandeiristas. Segundo ele, é sintomática dessa providência de utilização de restos antigos a existência da taipa de pilão somente nas paredes portantes do pavimento térreo que, por sinal, guarda notável semelhança em sua planta com as casas rurais do século XVIII' (FIGURAS 1, 2).

O sobrado ainda era a residência de Carlos Vasconcelos e família quando abrigou os cento e trinta e três republicanos para o encontro político que o tornaria famoso mais tarde. O objetivo maior do conclave era organizar o movimento republicano na então Província de São Paulo, depois da repercussão do Manifesto de 1870 divulgado no jornal A República, do Rio de Janeiro. A capital e diversas cidades candidataram-se para sediar o encontro, mas ltu foi escolhida por eleição, em razão das articulações entabuladas pelos políticos locais. A reunião compareceram observadores do Rio de Janeiro e representantes

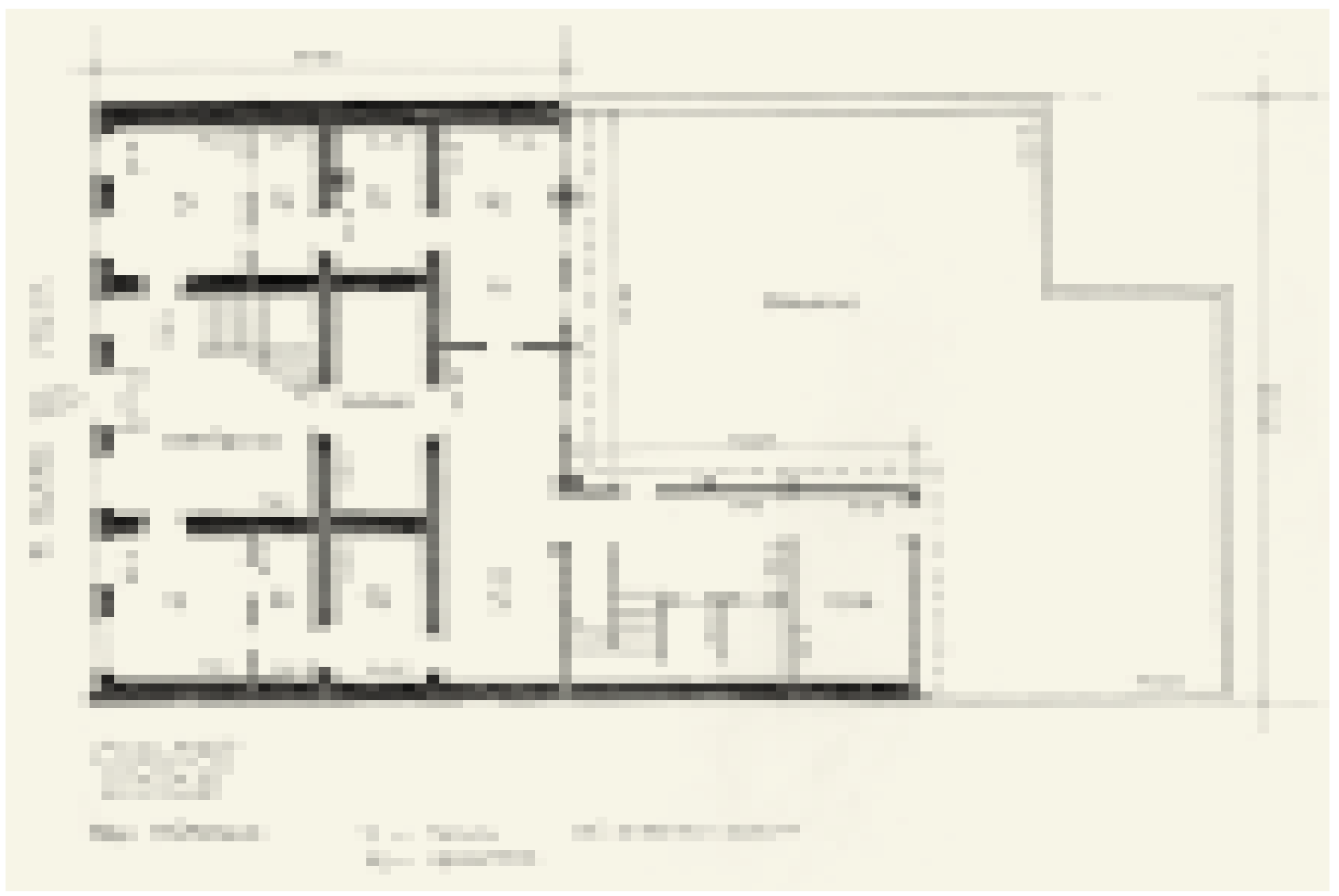

FIGURA 1 - Casa da família Carlos Vasconcelos de Almeida Prado em Itu, 1867. Planta baixa, andar térreo, elaborada sob orientação de Antônio Luís Dias de Andrade, FAU-USP, 1986. Acervo do Museu Republicano Convenção de ltu - MP/USP. 
de dezesseis cidades paulistas: Itu, Jundiaí, Campinas, São Paulo, Amparo, Bragança, Moji-Mirim, Constituição (atual Piracicaba), Botucatu, Tietê, Porto Feliz, Capivari, Sorocaba, Indaiatuba, Belém de Jundiaí (atual Itatiba), Montemor e Jaú ${ }^{4}$. A data escolhida, 18 de abril de 1873, certamente é indício de que os republicanos queriam associar sua imagem ao progresso material de São Paulo: não por acaso, a Estrada de Ferro Ituana tinha sido inaugurada no dia anterior, em solenidade na qual os republicanos tinham disputado espaços e discursos com os delegados do governo provincial (CANABRAVA, 1971)5. O local do encontro, - imenso sobrado em frente à lateral da lgreja Matriz Nossa Senhora da Candelária, desvela a hegemonia do grupo liderado pelos irmãos Carlos e José Vasconcelos de Almeida Prado, que no papel de anfitriões não queriam perder a oportunidade de exercer maior controle sobre o encontro.

conclave, até então denominado reunião, recebeu pela primeira vez a designação de convenção no Correio Paulistano, em sua edição de 25 de abril de $1873^{6}$. O jornal noticiou o evento sem lhe dar muito destaque. Entretanto,

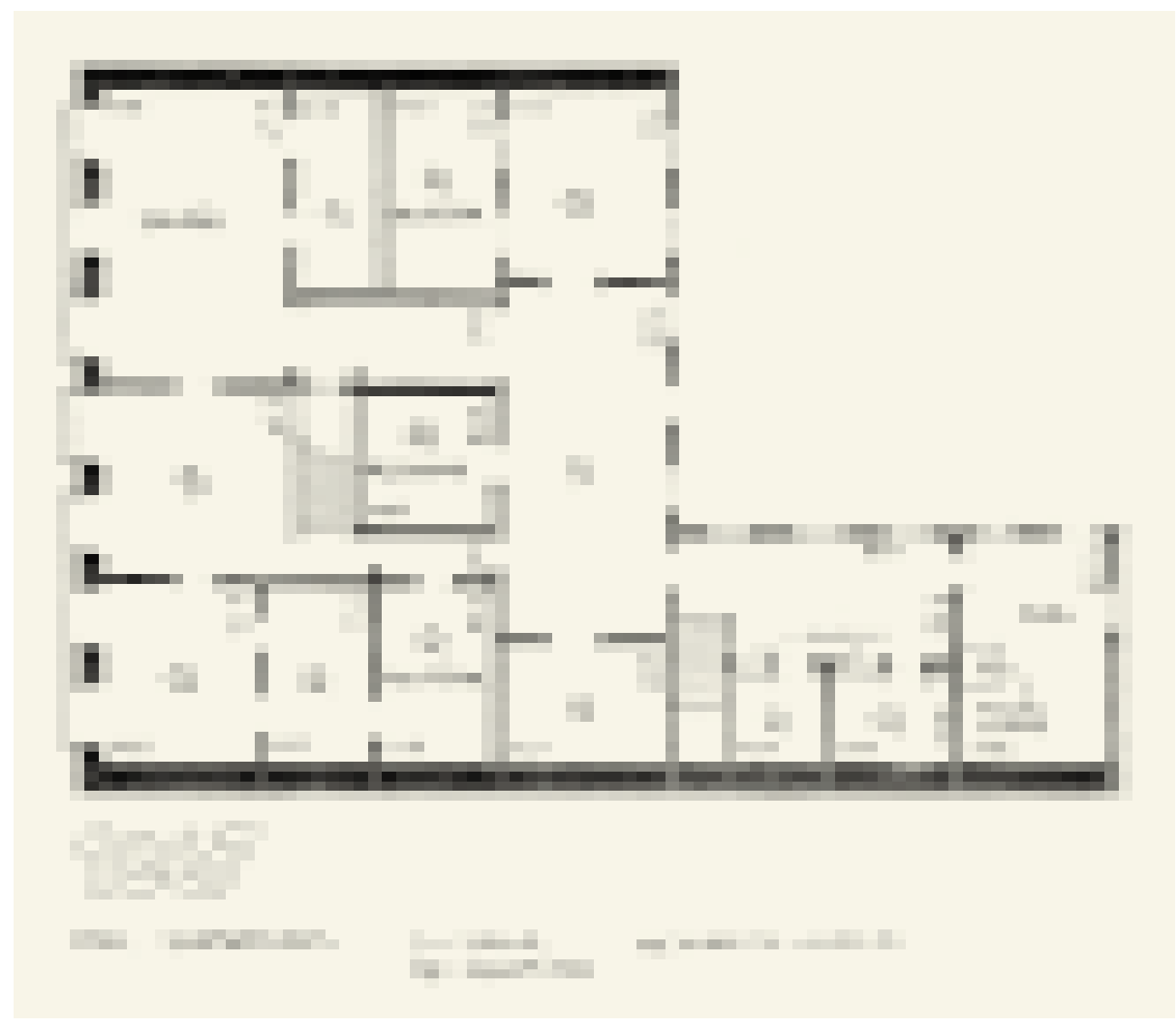

4. Ata da Convenção de Itu, manuscrito original do Museu Republicano "Convenção de Itu" reproduzido em: Solenização do cinqüentenário da Convenção de Itu, realizada a 18 de abril de $1923 \mathrm{com}$ a instalação do Museu Republicano "Convenção de Itu" pelo Governo do Estado de São Paulo a 18 de abril de 1923. São Paulo: Companhia Melhoramentos, 1923,p.93-100; eTAUNAY, Afonso E. Guia do Museu Republicano "Convenção de Itu”. São Paulo: Departamento Estadual de Informações, 1946.p.61-66.

5. Em São Paulo a construção das ferrovias, em grande parte, foi um investimento dos próprios fazendeiros de café. CANABRAVA, Alice P. A grande lavoura. In: HOLANDA, Sérgio Buarque (Ed.). História geral da civilização brasileira. O Brasil monárquico - Declínio e queda do Império, t. II,v.5. São Paulo: Difusão Européia do Livro, 1971. p. 92. Cesário Mota Júnior descreve a festa da inauguração da Estrada de Ferro Ituana no documento Recordações Históricas (1873), manuscrito do acervo do Museu Republicano "Convenção de Itu"। MP-USP.O documento foi publicado em: Solenização do cinqüentenário da Convenção de Itu, op.cit., p. 86-91; e TAUNAY, Afonso E. Guia do Museu Republicano "Convenção de Itu". op.cit., p. 67-72.

6. Correio Paulistano, Edição 4992, 25 de abril de 1873, Crônica Política $-A$ reunião de Itu, p. 1 . Para acompanhar o desenvolvimento do partido

FIGURA 2 - Casa da família Carlos Vasconcelos de Almeida Prado em Itu, 1867. Planta baixa, primeiro andar, elaborada sob orientação de Antônio Luís Dias de Andrade, FAU-USP, 1986. Acervo do Museu Republicano Convenção de ltu - MP/USP. 
depois da Convenção de Itu ver: BRASILIENSE, Américo. Os programas dos partidos e o segundo império. Brasília:Senado Federal; Rio de Janeiro: Fundação Casa de Rui Barbosa, 1979

7. A manifestação do interesse na preservação da "Casa da Convenção" pode ser acompanhada através dos jornais de Itu do final do século XIX e primeiros anos do século $\mathrm{XX}$, em coleções existentes na biblioteca do Museu Republicano "Convenção de Itu”/MP-USP. com o passar do tempo, à reunião foram atribuídos significados que pouco a pouco a transformaram na Convenção de ltu, o dia de sua realização passou a ser lido como a data de fundação do Partido Republicano Paulista, e a antiga residência tornou-se conhecida como a Casa da Convenção (BRASILIENSE, 1979).

Américo Brasiliense de Almeida Melo, que desempenhou a função de secretário na reunião de 18 de abril de 1873, escreveu em 1891, momento em que ocupava o cargo de presidente do Estado de São Paulo:

Assumi o difícil encargo [referia-se à presidência do Estado] com a mesma serenidade de ânimo, com a mesma calma e com a mesma convicção de bem, que me levaram àquela, já hoje célebre, reunião solenemente realizada a 18 de abril de 1873 e que passará à História com a denominação de Convenção de ltu.

Pouco tempo depois da manifestação de Américo Brasiliense, os republicanos paulistas passaram a demonstrar interesse na preservação da casa de ltu’. Mas a compra do imóvel pelo governo do Estado se deu somente três décadas depois, num momento em que o PRP já começava a sentir os primeiros sinais de desgaste, após a longa hegemonia iniciada com a subida ao poder dos

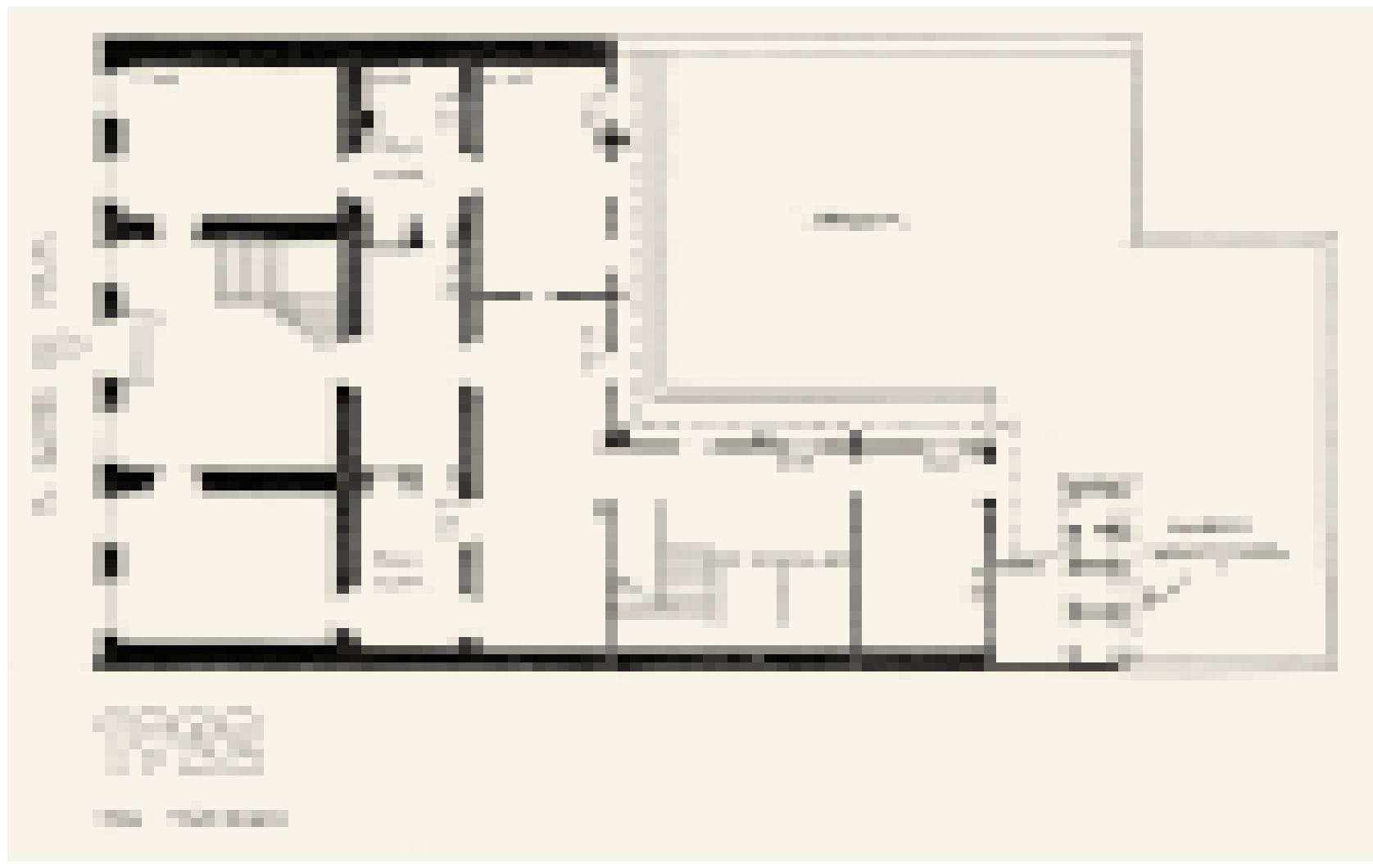

FIGURA 3 - Edifício do Museu Republicano Convenção de ltu, 1922. Planta baixa, andar térreo, elaborada sob orientação de Antônio Luís Dias de Andrade, FAU - USP, 1986. Acervo do Museu Republicano Convenção de ltu - MP/USP. 
representantes da cafeicultura paulista nos governos de Prudente de Moraes e Campos Sales.

Partido Republicano Paulista explorava a comemoração do cinqüentenário da Convenção, em razão de seu valor simbólico, e a criação do Museu Republicano como instrumentos de busca no passado de uma legitimidade histórica que pudesse ser manipulada a favor de sua estratégia de dominação. A aquisição do lugar do acontecimento da Convenção deveria ser a primeira etapa, com a qual a casa passava da condição simbólica privada para a administração pública do simbólico (SILVA, 2002; SODRÉ, 2002)․ Em 23 de dezembro de 1921 a Câmara dos Deputados de São Paulo aprovou a Lei n. 1856, autorizando a compra da Casa da Convenção. O deputado Mário Tavares deixou bem clara aquela preocupação no discurso que fez durante os debates do projeto:

A assembléia soleníssima, em que foram tomadas deliberações fundamentais e vitais para a arregimentação democrática, realizou-se em ltu e teve a denominação de Convenção de ltu. [...] Se ali nasceu o Partido Republicano Paulista, que foi tantos anos
8. SODRÉ, Muniz. Semiologia de uma casa-museu. Jornada Museo-lógica: notícias sobre museus-casas, Rio de Janeiro: Fundação Casa de Rui Barbosa (Papéis Avulsos), 43, p. 7-13, 2002; SILVA, Helenice Rodrigues. "Rememoração"/comemoração: as utilizações sociais da memória. Revista Brasileira de História, São Paulo:ANPUH/ Humanitas Publicações, v. 22, n.44, p. 425-438, 2002.

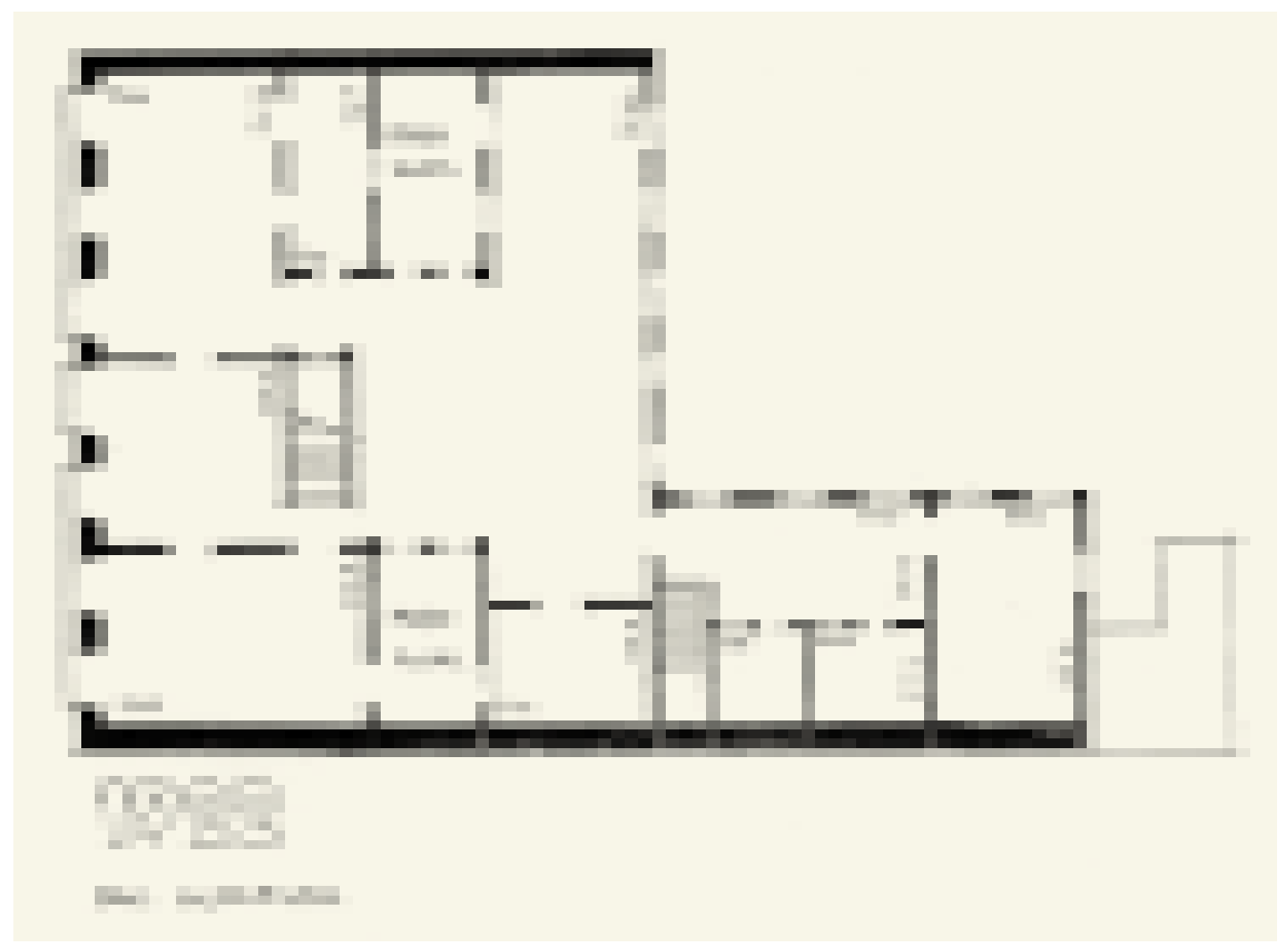

FIGURA 4 - Edifício do Museu Republicano Convenção de ltu, 1922. Planta baixa, primeiro andar, elaborada sob orientação de Antônio Luís Dias de Andrade, FAU - USP, 1986. Acervo do Museu Republicano Convenção de ltu - MP/USP. 
9. O discurso do deputado MárioTavares está reproduzido em: Solenização do cinqüentenário da Convenção de Itu,op.cit., p.14.

10. Lei 1856 de 29 de dezembro de 1921 e Decreto 3.579 de 12 de fevereiro de 1923 , documentos reproduzidosemSolenização do cinqüentenário da Convenção de Itu, op.cit., p.17-18 o exemplo da abnegação, da disciplina e do bom doutrinamento, servindo de estímulo às outras agremiações nas antigas províncias, eu, fortalecendo-me no revigoramento daquela convicção, na lembrança daquelas doutrinas, seguro e tranqüilo, julguei-me capaz de receber a comissão de constituir com os legítimos representantes do povo o Estado de S.Paulo, autônomo, republicano e forte na grande República Brasileira. [...] Celebremos o passado. Entreguemos a casa modesta, onde nasceram o Partido Republicano e a democracia brasileira, ao preito do povo e especialmente da mocidade, para que ela transmita, de geração a geração, o fogo sagrado desta fé vigorosa nos destinos da nossa terra $[\ldots]^{9}$.

governo estadual investiu quarenta contos de réis na incorporação do imóvel ao patrimônio público e liberou o crédito de oitenta contos de réis para as despesas orçadas com a reforma e a adaptação da antiga residência assobradada ao novo programa de uso ${ }^{10}$.

Washington Luís Pereira de Souza, presidente do Estado de São Paulo, escolheu o historiador Afonso d'Escragnolle Taunay para supervisionar a intervenção

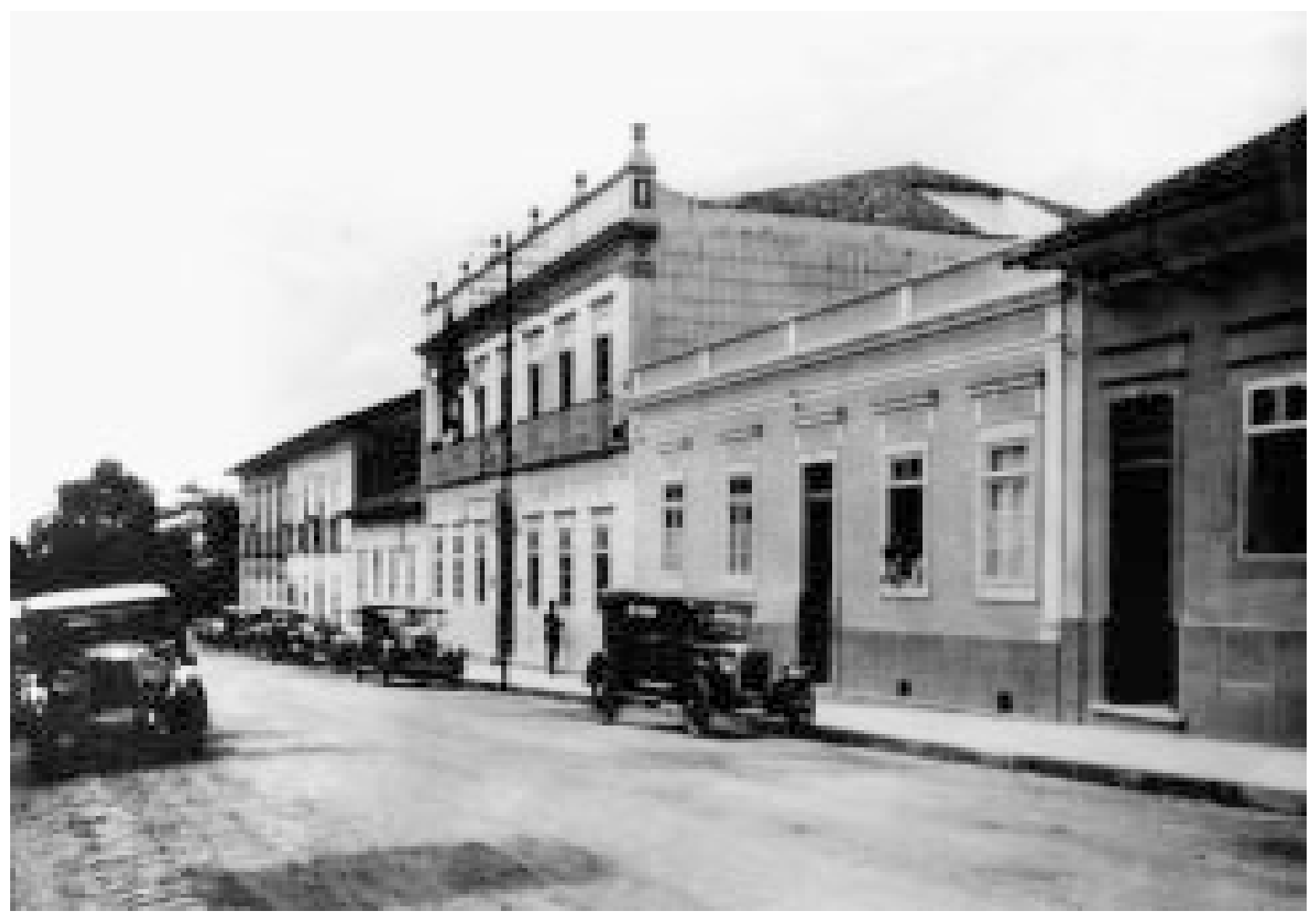


de adaptação dos espaços internos do sobrado ao programa do museu. Taunay, que então dirigia o Museu Paulista, também foi encarregado da tarefa de organizar a nova instituição museológica. Os engenheiros Carlos Quirino Simões e Achilles Nacarato fizeram o projeto de reforma do edifício a pedido da Secretaria de Estado dos Negócios da Agricultura, Comércio e Obras Públicas. Na correspondência de 18 de novembro de 1922, que endereçaram ao diretor de obras, os engenheiros justificaram a intervenção programada:
11. Ofício de 18 de novembro de 1922 , dossiê Museu Histórico Republicano.Secretaria da Viação e Obras Públicas - Diretoria de Obras Públicas. Autos 527 de 1922

Os reparos, de pequena monta, se justificam por suas próprias naturezas, e representam pequenos cuidados para manter em bom estado de conservação as várias partes do prédio; tive, porém, de computar a reforma total do telhado, tal o estado impressionante em que se apresenta, impróprio para uma moradia comum e muito menos para um museu; cobertura construída em 1867 e retocada desorganizadamente, por várias vezes, ali se notam cumieira, rincões, terça, caibros e ripas em madeira roliça e fasquias de coqueiros de mistura com madeira serrada e lavrada, sem uniformidade de dimensões, sem regularidade na disposição

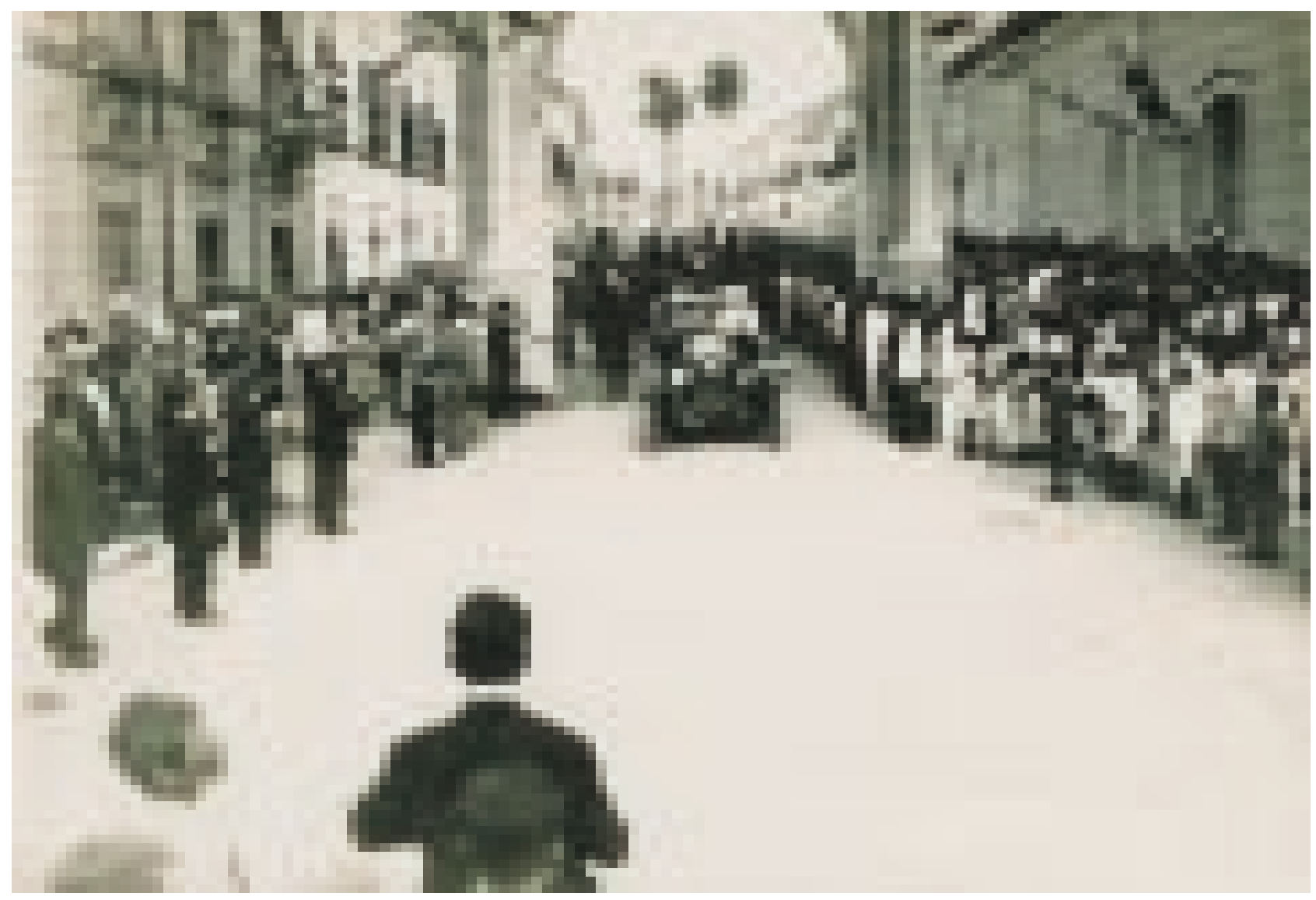

FIGURA 6 - Inauguração do Museu Republicano Convenção de Itu, 18 de abril de 1923.

Fotografia de Frederico Egner. Acervo do Museu Republicano Convenção de ltu - MP/USP. 
12. Informação n. 58 , de 28 de abril de 1923, dossiê Museu Histórico Republicano. Secretaria da Viação e Obras Públicas - Diretoria de Obras Públicas. Autos 527 de 1922. e apodrecidas em grande parte. Notarei que as telhas datam da época citada e as tesouras, além das dimensões reduzidas, têm falta de peças, supridas por pontaletes e escoras. Na pintura, ainda cumprindo vossas ordens, substitui as partes em papel por uma caiação sóbria e que satisfaça os fins em vista. Os preços compostos do meu orçamento são os mesmos da tabela organizada no escritório técnico para o estudo de adaptação, ali em andamento, do prédio da Convenção para um museu de relíquias republicanas ${ }^{1 !}$. (FIGURAS 3, 4).

As obras foram executadas apressadamente, para que tudo se concluísse na data aprazada. Às vésperas da inauguração o responsável participava ao diretor de obras:

Está concluída e recebida, desde 18 do corrente, a reforma do prédio destinado a um museu de relíquias republicanas. Os trabalhos obedeceram ao projeto e orçamento elaborados; foram executadas todas as modificações que o sr. Dr. Presidente do Estado determinou em sua visita de 9 do corrente... ${ }^{12}$

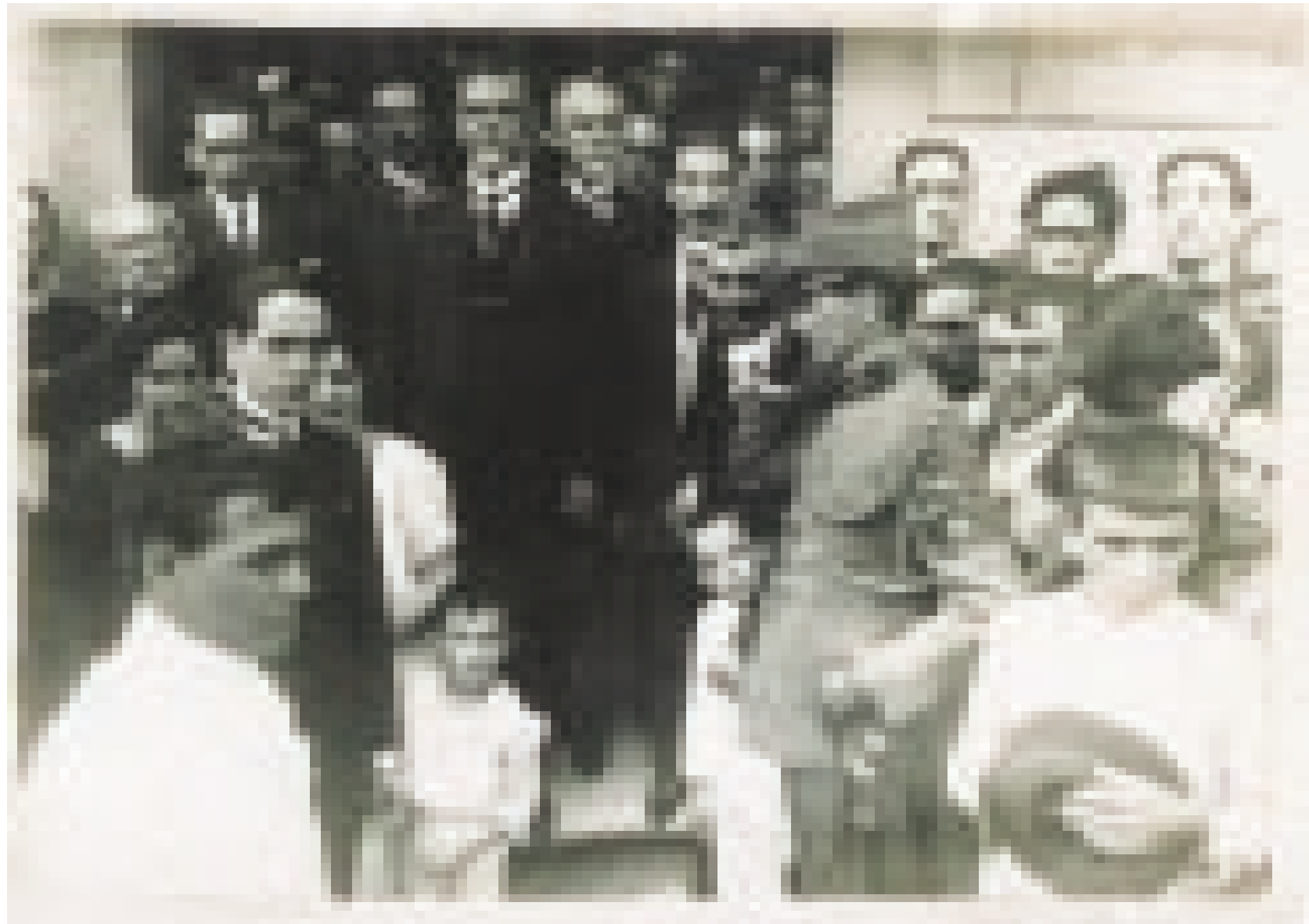

FIGURA 7 - Washington Luís na entrada do Museu Republicano Convenção de ltu no dia da sua inauguração. Fotografia de Frederico Egner. Acervo do Museu Republicano Convenção de Itu MP/USP. 
Alguns cômodos deixaram de existir para ceder espaço a duas áreas de iluminação, e paredes foram derrubadas para abrir um grande salão no pavimento superior. A abertura desse salão foi decidida pelo próprio presidente Washington Luís, durante visita de inspeção realizada na companhia do deputado Carlos de Campos e do secretário de Estado dos Negócios da Agricultura, Comércio e Obras Públicas Heitor Penteado. A cúpula do PRP acompanhou de perto o andamento das obras e determinou que nos cômodos utilizados pela convenção republicana não se fizesse qualquer mudança, e neles "absolutamente não se tocou; estão tal qual eram a 18 de abril de 1873"13 (FIGURA 5).

Pronto o cenário, montou-se a solenidade da inauguração do Museu Republicano e do cinqüentenário da Convenção de ltu. $\bigcirc$ evento tinha que ser uma grande festa do PRP. Na rua fronteira ao sobrado ajuntou-se a multidão para ver a chegada da comitiva do presidente do Estado. O grande salão do pavimento superior, que surgiu depois da derrubada das paredes que confinavam antigas
13. Solenização do cinqüentenário da Convenção de Itu, op.cit., p.19.

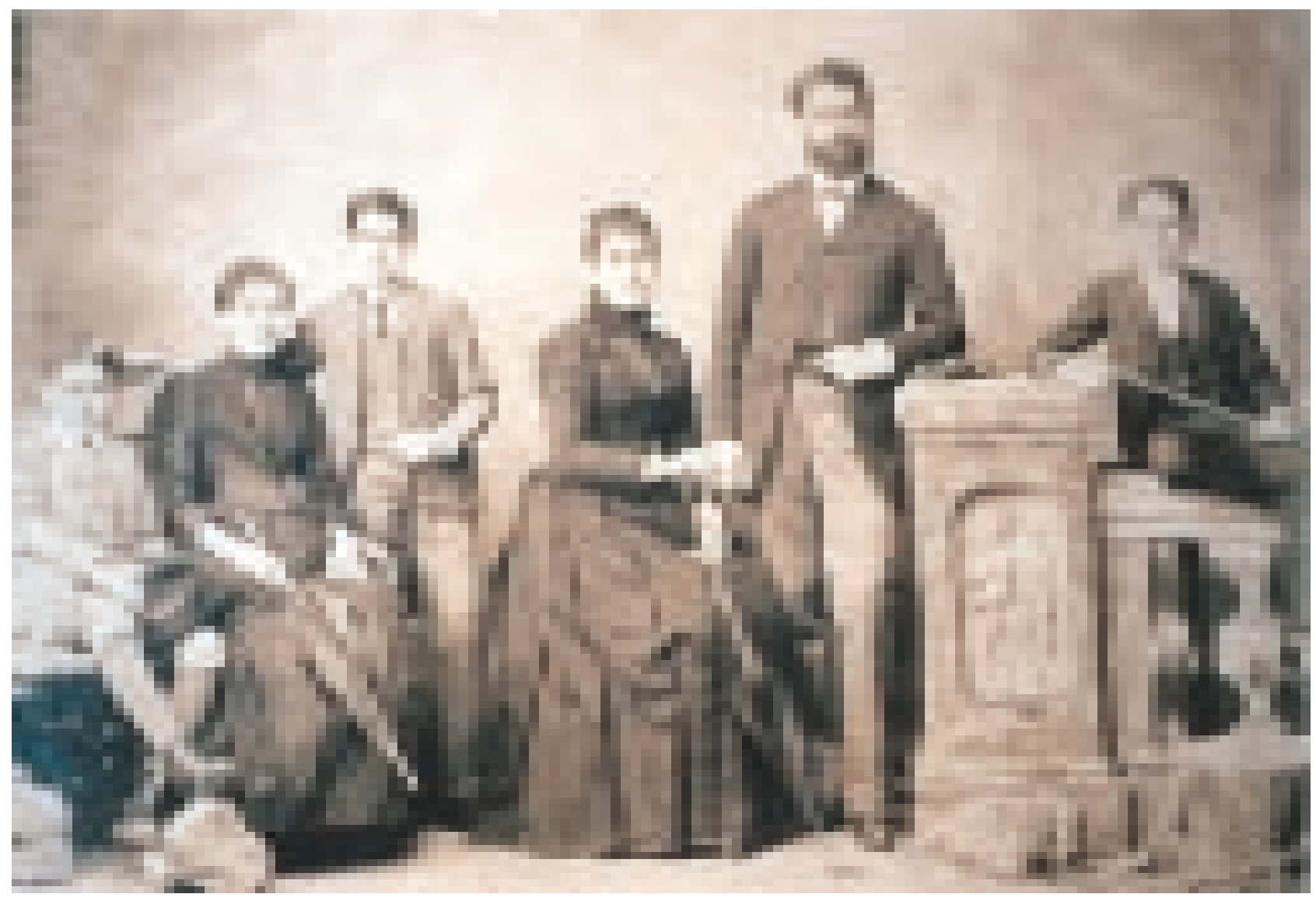

FIGURA 8 - Família Carlos Vasconcelos de Almeida Prado, 1886. Acervo do Museu Republicano Convenção de ltu - MP/USP. 
14. Comentário do advogado ituano Ermelino Maffei, em que faz referência ao célebre dito do republicano Aristides Lobo, segundo o qual "o povo assistiu bestializado à Proclamação da República". Em 18 abril de 1923 o então jovem estudante Maffei juntou-se ao grupo de acadêmicos do Largo de São Francisco, que foi a Itu para assistir à inauguração do Museu Republicano "Convenção de Itu”. No comentário, em palestra proferida na comemoração do aniversário do Museu em abril de 1988, alcovas, acomodou os filiados do partido, secretários de Estado, acadêmicos de Direito, deputados, vereadores, prefeitos, jornalistas, escritores, convencionais e familiares de convencionais já falecidos, além de curiosos que mais uma vez "a tudo assistiam bestializados" (CARVALHO, 1987) ${ }^{14}$. No discurso que convinha à ocasião, rodeado dos presentes e dos retratos a óleo dos "convencionais de 1873", Washington Luís disse ao público que o ouvia em absoluto silêncio, na avaliação de uma testemunha ocular ${ }^{15}$.

Essa festa de hoje, exclusivamente cívica, puramente republicana, cultuando o passado democrático, presta uma homenagem respeitosa aos homens extraordinários da Convenção de ltu, cujos sobreviventes emprestam a esta assembléia uma solenidade venerável; significa a tranqüilidade da hora presente diante das realizações feitas; exprime a confiança, que não desfalece, nos tempos por vir, e mostra inequivocamente, numa reafirmação imponente e comovedora que, cônscios das grandes responsabilidades que thes cabem no regime, assim no passado como no presente, não perderam os paulistas as características do seu gênio. Intemeratos, fortes, desprendidos, estão sempre juntos, prontos, ao primeiro toque de reunir, na defesa da República. A festa de hoje pertence indiscutivelmente ao Partido Republicano Paulista, cujas origens se diluem no

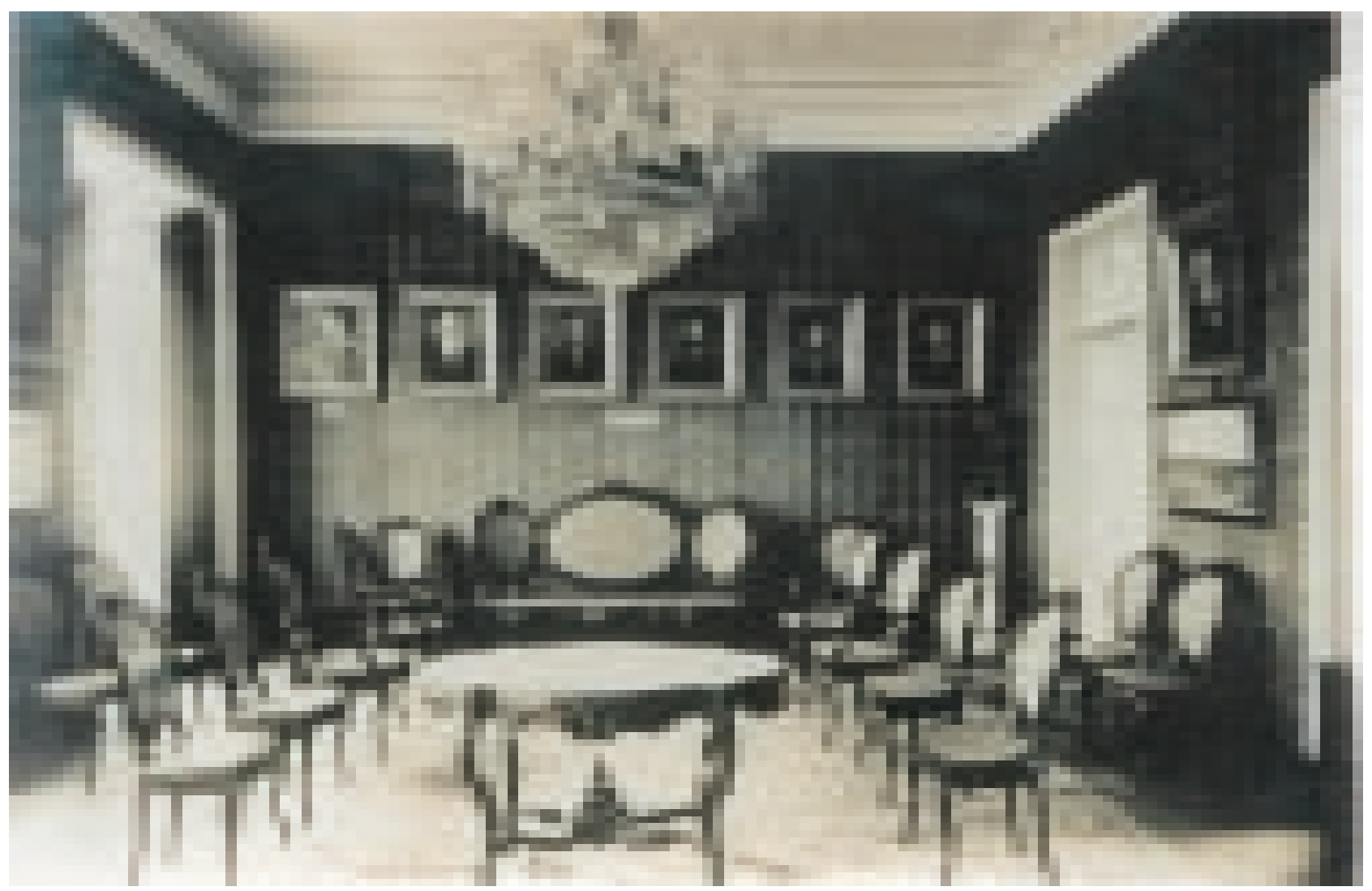


passado, mas se juntam na Convenção de Itu, avolumando-se cada vez mais e continuamente na propaganda, na proclamação, na defesa e na manutenção da República ${ }^{16}$ (FIGURA 6).

$\bigcirc$ presidente foi aplaudido demoradamente. Ao findarem os discursos e os cumprimentos de praxe, Washington Luís desceu os degraus de acesso ao saguão da entrada e descerrou a lápide, onde ele próprio mandara gravar em bronze:

Comemorando a efeméride cinqüentenária e ilustre de 18 de abril de 1873 com a instalação deste instituto destinado a celebrar os fastos do republicanismo paulista, grato e reverente preito consagra o Governo do Estado de São Paulo, por seu presidente Washington Luís Pereira de Souza, a memória benemérita dos que na assembléia imorredoura da Convenção de ltu, neste edifício reunida, atestaram à face da Nação Brasileira o despontar e a energia do Partido Republicano Paulista fazendo ouvir as vozes de sua fé e as de sua esperança no triunfo definitivo da República Federativa.
Maffei citava: CARVALHO, José Murilo. Bestializados ou bilontras? In: Os bestializados. O Rio de janeiro e a República que não foi. São Paulo: Companhia das Letras, 1987.p. 140-160.

15. Solenização do cinqüentenário da Convenção de Itu, op.cit.,p.36.

16. O discurso de Washington Luís está reproduzido em: Solenização do cinqüentenário da Convenção de Itu, op.cit. p. 36-39.

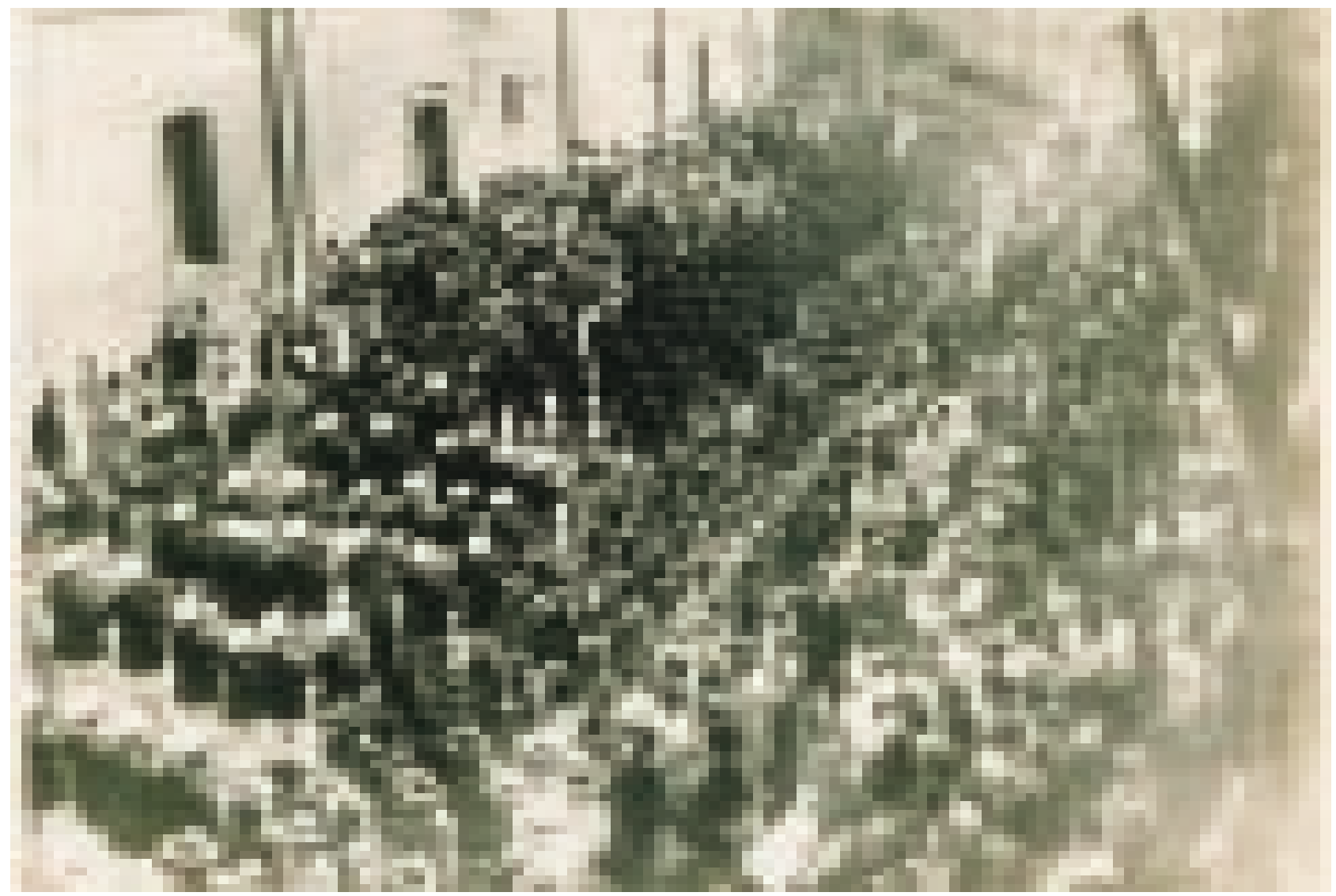

FIGURA 10 - Desfile de bandas de música em frente ao Museu Republicano Convenção de ltu no dia da festa da inauguração, 18 de abril de 1923. Fotografia de Frederico Egner. Acervo do Museu Republicano Convenção de ltu - MP/USP. 
Artigo apresentado em $11 / 2003$.

17. Ofício de Afonso $\mathrm{E}$ Taunay a Washington Luís de 20 de novembro de 1923, dossiê Museu Histórico Republicano. Secretaria da Viação e Obras Públicas - Diretoria de Obras Públicas.Autos 527 de 1922.

18. Solenização do cinqüentenário da Convenção de Itu, op.cit., p.19,23-35 (Celebração do cinqüentenário da Convenção de Itu). Embora não conste o seu nome como responsável pela publicação, Afonso E. Taunay foi certamente $o$ organizador desta plaqueta, como pode ser deduzido do ofício que ele remeteu a Washington Luís em 28 de maio de 1923, dossiê Museu Histórico Republicano. Secretaria da Viação e Obras Públicas - Diretoria de Obras Públicas.Autos 527 de 1922

19. Washington Luís acompanhava a produção dos retratos através de conversas pessoais com Taunay e de correspondência, como os ofícios do diretor do Museu Paulista ao presidente do Estado, datados de 17 de fevereiro e de 30 de março de 1923, dossiê Museu Histórico Republicano. Secretaria da Viação e Obras Públicas - Diretoria de Obras Públicas.Autos 527 de 1922

20. TAUNAY, Afonso E Guia do Museu Republicano "Convenção de Itu". São Paulo: Departamento Estadual de Informações, 1946. p.11;TAUNAY,Afonso E. Relatório referente ao ano de 1923 , apresentado a 2 de fevereiro de 1924 ao "Excelentíssimo Senhor Secretário do interior, Doutor Alarico
Fundida em bronze pelo artesão Roque de Mingo, a placa reproduz o modelo entalhado em madeira por $\mathrm{H}$. Bakkenist, o mesmo autor da maquete São Paulo em 1840, executada para o Museu Paulista. Depois de servir de molde da placa de bronze da inauguração, o modelo em madeira foi restaurado e presenteado a Washington Luís. Taunay, autor da iniciativa, mandou o presente ao destinatário acompanhado de um ofício no qual reforçava o papel do presidente de Estado na criação do museu - "espero que cause prazer este objeto que recorda uma fundação a V.Exa. devida"17 (FIGURAS 7, 8).

Na data da inauguração, marcada para coincidir com o cinqüentenário da Convenção de Itu, a exposição do Museu Republicano ainda não estava concluída. Taunay incumbiu-se de justificar a situação - "um instituto desta natureza só passados anos assume proporções consideráveis, não se improvisando museus", e de descrever a comemoração ${ }^{18}$. Ele atribuiu ao evento um caráter espetacular, digno de ser incluído no panteão de festas e efemérides nacionais. Como ele mesmo conta (TAUNAY, 1923), inaugurou-se o museu com uma incompleta "galeria de retratos de vultos eminentes do republicanismo": signatários do Manifesto de 1870, propagandistas da república, membros da Convenção e membros do governo provisório da república. Washington Luís acompanhou passo a passo o processo de escolha dos retratados e dos pintores contratados para a produção dos retratos a óleo ${ }^{19}$. Depois da inauguração, o acervo começou a ser ampliado por meio de compras e de doações de familiares dos convencionais de 1873, membros do PRP e do próprio Washington Luís. Uma das primeiras aquisições foi - mobiliário indicado por José Vasconcelos de Almeida Prado e Olímpia Augusta da Fonseca Almeida Prado, viúva de Carlos Vasconcelos de Almeida Prado, com o intuito de encenar parte do ambiente da residência em 1873. Taunay explica que o objetivo do museu era comemorar a Convenção de ltu e os grandes homens da fase de propaganda até a Proclamação da República, e ao mesmo tempo por se achar instalado numa residência típica do século XIX, Ihe ocorrera a idéia de também fazer dele um museu de artes decorativas, "dando aos visitantes a idéia do que eram o mobiliário e a ornamentação de uma casa rica brasileira pelas vizinhanças de 1870 com o seu feitio típico de disparidade muito de bric à brac, pela mistura de estilos e procedências" (TAUNAY, 1946)20. Como de costume, depois das buscas e localização do mobiliário, Taunay submeteu a idéia a Washington Luís:

Aqui the remeto uma série de fotografias demonstrativas da nova arrumação do seu museu. Pelo Sr. Dr. Alarico soube da sua decisão sobre o caso da mobília. Vamos a ver se se descobre outra em melhores condições, porque como verá da fotografia ela vai admiravelmente naquele ambiente. Melhor é impossível até. Só falta o tapete e o lampião de querosene na mesa do centro e o Sr. se verá transportado à sua infância, à casa paterna, ou avoenga, como na Macaé ${ }^{21}$.

Convencido, Washington Luís consentiv e o secretário do Interior Alarico Silveira liberou uma verba extraordinária para a compra da mobília de Felício Marmo, de tradicional família ituana. $\bigcirc$ tapete e o lampião de querosene foram comprados logo em seguida (FIGURA 9).

A transformação da casa em museu consistiu em uma estratégia de objetivação da memória, isto é, do lugar simbólico em que se realizou um evento significativo a um determinado partido políico, o PRP - Partido Republicano Paulista, para legitimar historicamente a hegemonia do grupo social ligado aos interesses dos grandes cafeicultores de São Paulo, que lhe dava suporte (FIGURA 10). 
REFERÊNCIAS

BRASILIENSE, Américo. Os programas dos partidos e o segundo império. Brasília: Senado Federal; Rio de Janeiro: Fundação Casa de Rui Barbosa, 1979.

CANABRAVA, Alice P. A grande lavoura. In: HOLANDA, Sérgio Buarque (Ed.). História geral da civilização brasileira. O Brasil monárquico - Declínio e queda do Império, t. II, v.5. São Paulo: Difusão Européia do Livro, 1971.

CARVALHO, José Murilo. Bestializados ou bilontras? In: Os bestializados. O Rio de Janeiro e a República que não foi. São Paulo: Companhia das Letras, 1987.p. 140-160.

LEMOS, Carlos A. C. Casa Paulista: história das moradias anteriores ao ecletismo trazido pelo café. São Paulo: Editora da Universidade de São Paulo, 1999.

LEMOS, Carlos. Testemunha da história. Boa Vida, Itu, v.15, n. 178, 2003.

SILVA,Helenice Rodrigues."Rememoração"/comemoração:as utilizações sociais da memória.Revista Brasileira de História, São Paulo:ANPUH/Humanitas Publicações, v. 22, n.44, p. 425-438, 2002.

SODRÉ,Muniz. Semiologia de uma casa-museu.Jornada Museológica:notícias sobre museus-casas, Rio de Janeiro: Fundação Casa de Rui Barbosa (Papéis Avulsos), 43, p. 7-13, 2002;

TAUNAY, Afonso E. Solenização do cinqüentenário da Convenção de Itu, realizada a 18 de abril de 1923 com a instalação do Museu Republicano "Convenção de Itu” pelo Governo do Estado de São Paulo a 18 de abril de 1923. São Paulo: Companhia Melhoramentos, 1923.

TAUNAY, Afonso E. Guia do Museu Republicano “Convenção de Itu”. São Paulo: Departamento Estadual de Informações, 1946.
Silveira". Revista do $\mathrm{Mu}$ seu Paulista, t. 14, p. 793 807, 1926.

21. Carta de Afonso E. Taunay a Washington Luís, de 2 de junho de 1923, dossiê Museu Histórico Republicano. Secretaria da Viação e Obras Públicas - Diretoria de Obras Públicas.Autos 527 de 1922.

Artigo apresentado em $11 / 2003$. 
The two-storey house where Itu Convention was held, in the old Rua do Carmo, Inowadays Rua Barão do ltaim): a documental work of research

Anicleide Zequini Rossi

The text is about the results of a documental work of research (post-mortem inventory and Book of Notes) regarding the trajectory of the building in which The City of Itu (SP)'s Republican Museum (Museu Republicano na Cidade de ltu-SP) is installed, an extension of Museu Paulista - USP. Therefore, from all the pieces of information researched we can infer that the construction day of the building that shelters the museum, is a lot earlier than 1850, year which has been considered as such in many essays. This year registers, in fact, the presence of one of the families that lived in that building: the Almeida Prados that hosted the Conventionals of 1873.

KEYWORDS: Museu Republicano Convenção de Itu - MP/USP. Itu, History. Itu, Museum. Almeida Prado, Family.

Anais do Museu Paulista. São Paulo. N. Sér. v. 10/11.p.197-211 (2002-2003).

De casa a museu: 80 anos do Museu Republicano Convenção de ltu

Jonas Soares de Souza

O texto apresenta um panorama geral do processo de criação do Museu Republicano "Convenção de ltu" na década de 1920. Idealizado pelos republicanos paulistas, o projeto da instituição explorou o valor simbólico da "Convenção de ltu" e o significado do lugar de sua realização como recurso para ampliar a legitimidade histórica da hegemonia do Partido.

PALAVRAS-CHAVE:Arquitetura. Museu. Memória. Comemoração.

Anais do Museu Paulista. São Paulo. N. Sér. v. 10/11.p.213-225 (2002-2003)

From home to museum: 80 years of the Republican Museum (Museu Republicano) ltu Convention

Jonas Soares de Souza

This article presents a general overview of the creation process of Museu Republicano "Convenção de ltu" in the decade of 1920. Idealized by republicans from São Paulo, the institution's project has exploited the Convenção de ltu's symbolic values and the meaning of place where it was made as a resource to widen the historical legitimacy of the Party hegemony.

KEYWORDS:Architecture. Museum. Memory. Celebration.

Anais do Museu Paulista. São Paulo. N. Sér. v. 10/11.p.213-225 (2002-2003)

O Serviço de Objetos do Museu Paulista

Adilson José de Almeida, Angela Maria Gianeze Ribeiro, Heloisa Barbuy, Margarida Davina Andreatta Aborda a organização do Serviço de Objetos do Museu Paulista - curadoria de acervos e sistema de informação - e suas linhas de pesquisa: 1. Formação das coleções. 2. Formas alternativas de dinheiro. 3. Cultura visual no século XIX: museus exposições industriais e cidades / Comércio, industrialização e cultura material. 4. Arqueologia histórica e industrial. 5. Vida militar e cultura material.

PALAVRAS-CHAVE: Curadoria e pesquisa. Numismática. Coleção de veículos. Coleções militares. Cultura visual. Industrialização. Anais do Museu Paulista. São Paulo. N. Sér. v. 10/11.p.227-257 (2002-2003)

The Department of Object Collections of Museu Paulista

Adilson José de Almeida, Angela Maria Gianeze Ribeiro, Heloisa Barbuy, Margarida Davina Andreatta It focuses the organization of the Department of Object Collections of Museu Paulista - curatorship and information system - and its research directions: 1. Formation of the collections. 2. Money alternative forms. 3. Visual Culture in the 19th century: museums, industrial exhibitions and cities / Commerce, industrialization and Material Culture. 4. Historical and Industrial Archaeology. 5. Military life and Material Culture.

KEYWORDS: Curatorship and Research. Numismatic. Collection of Vehicles. Collection of Military Objects. Visual Culture. 